\title{
Activated lymph node $\mathrm{T}$ cells for systemic adoptive immunotherapy of malignant glioma
}

\section{Gregory E. Plautz, M.D., Gene H. Barnett, M.D., David W. Miller, M.D., Bruce H. Cohen, M.D., Richard A. Prayson, M.D., John C. Krauss, M.D., Mark Luciano, M.D., Ph.D., and Suyu Shu, Ph.D.}

Departments of Neurological Surgery, Neurology, and Pathology, and the Center for Surgery Research, The Cleveland Clinic Foundation, Cleveland Ohio

Ten patients with progressive primary or recurrent malignant glioma received systemic adoptive immunotherapy to determine the feasibility, toxicity, and potential therapeutic benefits of this treatment. Adoptive immunotherapy, the transfer of immune T lymphocytes, is capable of mediating the regression of experimental brain tumors in animal models. A rich source of tumor-immune T cells are lymph nodes (LNs) draining the tumor vaccine site. In this clinical study, patients were inoculated intradermally with irradiated autologous tumor cells and granulocyte-macrophage colony stimulating factor as an adjuvant. Cells from draining inguinal LNs, surgically resected 7 days after vaccination, were stimulated sequentially with staphylococcal enterotoxin A and anti-CD3, and a low dose of interleukin-2 (60 IU/ml) was used to expand the stimulated cells. The maximum cell proliferation was 350 -fold over 10 days of culture. The activated cells were virtually all T cells consisting of various proportions of CD4 and CD8 cells. These cells were given to patients by intravenous infusion at doses ranging from $9 \mathrm{X} 10^{8}$ to $1.5 \mathrm{X}$ $10^{11}$. There were no Grade 3 or 4 toxicities associated with the treatment. Following T cell transfer therapy, radiographic regression that lasted at least 4 months was demonstrated in three patients with recurrent tumors, and four patients remain alive more than 11 months after surgery. The remaining patients had progressive disease, and three patients required intervention with corticosteroid agents or additional surgery approximately 1 month following cell transfer. These findings demonstrate that adoptive immunotherapy can be administered in patients with glioma without causing significant toxicity. It appears that this experimental regimen can provide therapeutic benefits for some patients.

\section{Key Words * adoptive immunotherapy * T lymphocyte * malignant glioma * clinical trial * staphylococcal enterotoxin A}

Gliomas are the most frequent primary tumor of the central nervous system in adults, accounting for approximately $50 \%$ of brain tumors. Malignant gliomas, including anaplastic astrocytoma and glioblastoma multiforme (GBM), occur in four to six new cases per 100,000 people per year. Aggressive multimodality therapy, including surgical resection, radiotherapy, and chemotherapy, were documented to play a beneficial role nearly 20 years ago. $[48,49]$ Unfortunately, despite current therapy, recurrence is 
usually rapid, with the 2-year survival rate remaining at approximately $5 \%$. This difficult clinical situation has stimulated interest in additional approaches to the treatment of malignant gliomas. The use of tumor-reactive T lymphocytes for cancer therapy has particular theoretical appeal as an adjunct to current therapies.

In several clinical trials, the adoptive transfer of tumor-reactive $T$ cells has been shown to mediate the regression of established tumors in a small number of patients with extracranial tumors.[10,11,17,36,44] The quality of the $\mathrm{T}$ cells is probably the most important component of adoptive immunotherapy, and the source, specificity, and number of T cells are essential determinants of efficacy. Using preclinical animal tumor models, we have determined that lymph nodes (LNs) draining a tumor inoculum are the optimum source of $T$ cells sensitized to specific tumor antigens, in contrast to other lymph tissues.[12,42,51] After ex vivo stimulation and expansion, these cells developed into potent therapeutic effector cells which, on systemic transfer, were capable of mediating the regression of tumors established in the lung and skin as well as in the brain.[22,33,51] The reactivity of the tumor-draining LN T cells was exquisitely specific for the tumor that provided the in vivo stimulation. Independently derived tumors of similar histological composition were not affected, suggesting that tumor-specific rather than tissue-restricted antigens were the dominant antigens in this immune response. Although similar tumor-reactive $\mathrm{T}$ cells may exist in cancer patients, there is evidence that their ability to proliferate and function is suppressed.[1,16]

Most of the clinical applications of adoptive immunotherapy have been for melanoma and renal cell carcinoma. There are theoretical reasons to suggest that the application of T cell immunotherapy delivered to malignant brain tumors might be difficult. First, the brain is considered an immune-privileged site, and diminished immune responses are generated against antigens introduced into the central nervous system.[19,31] Second, it is well documented that many gliomas release substances, such as transforming growth factor- $\beta$, prostaglandin $E_{2}$, and interleukin (IL)-10, that cause immunosuppression. $[8,15,20,21,30]$ Third, because of the requirement for structural integrity and confined anatomical space, the brain may not tolerate the inflammation associated with an immune reaction. Despite these concerns, we have demonstrated in animal models that adoptive transfer of activated tumor-draining LN T cells mediated the regression of experimentally established intracranial malignancies.[22,45,47] Transferred intravenously, T cells infiltrated intracranial tumors, demonstrating that there is no intrinsic barrier to the migration of activated $\mathrm{T}$ cells into intracranial tumors. The $\mathrm{T}$ cell infiltrate was localized to the tumor; very few T cells were present in the normal brain parenchyma.[34] A murine glioma was also successfully treated by adoptive transfer of activated tumor-draining LN T cells, and cured mice were neurologically normal and resisted a second intracranial tumor challenge.[35] These data indicated that adoptive immunotherapy might be an alternative treatment for humans with malignant glioma. A phase I clinical trial was initiated to establish whether adoptive immunotherapy was feasible in patients with recurrent or residual malignant astrocytoma and to determine the toxicity associated with this treatment.

\section{CLINICAL MATERIAL AND METHODS}

\section{Protocol Inclusion Criteria}

Eligible patients had pathologically confirmed Grade III or IV malignant astrocytoma. All patients received radiotherapy and, in some cases, chemotherapy following their primary diagnosis. Pathological analysis confirmed recurrent disease in eight patients, and clear radiographic evidence of residual/recurrent tumor following radiotherapy was demonstrated in the two patients with primary 
GBM. The study was approved by the institutional review board, and written informed consent was obtained from all patients. Tissue was obtained at the time of medically necessary surgical debulking or resection. Eligibility criteria included a performance status of 0 to 1 on the Eastern Cooperative Oncology Group scale; clinical stability without concurrent corticosteroid treatment in excess of physiological replacement at the time of vaccination or lymphocyte infusion; white blood cell count greater than $2 \times 10^{3} / \mu 1$, platelet count greater than $100 \times 10^{3} / \mu$, blood urea nitrogen level less than 25 $\mathrm{mg} / \mathrm{dl}$, creatinine level less than $1.8 \mathrm{mg} / \mathrm{dl}$, serum glutamic oxabacetic transaminase level less than two times normal upper limit, and total bilirubin level less than $3 \mathrm{mg} / \mathrm{dl}$; and negative serology for hepatitis B virus and human immunodeficiency virus.

No patient received chemotherapy, radiotherapy, or immunotherapy in the 4 weeks preceding vaccination. Pregnant or lactating women were excluded, as were patients with radiation implants, active or unexplained febrile illness, active collagen vascular disease, or who were otherwise immunologically compromised due to chronic conditions.

\section{Vaccination Procedures}

Fresh tumor specimens obtained at the time of tumor resection were transported at $4 \check{\mathrm{s} C}$ in sterile Hanks' balanced salt solution (HBSS) to a dedicated tissue culture hood. Necrotic tumor, connective tissue, and blood clots were removed, and the tissue was minced with a scalpel. Single-cell suspensions were prepared by digestion in $40 \mathrm{ml}$ of HBSS containing $4 \mathrm{mg}$ DNase I, $40 \mathrm{mg}$ collagenase type IV, and $100 \mathrm{U}$ hyaluronidase type $\mathrm{V}$ at room temperature for 3 hours. Cells were filtered through a layer of No. 100 nylon mesh and washed twice in HBSS. Tumor cultures were initiated by adding cells to fibronectin-coated tissue culture flasks and cultured in Dulbecco's modified Eagle's medium (84\%), supplemented with X-VIVO $15(10 \%)$, human AB serum (5\%), G5 (1\%), and hydrocortisone (10 $\mu \mathrm{g} / \mathrm{ml})$ at $37 \check{\mathrm{s}} \mathrm{C}, 5 \% \mathrm{CO}_{2}$ in a humidified incubator. Routinely, short-term culture of tumor cells has been successful in approximately $70 \%$ of cases. Either cultured or fresh-frozen tumor cells were used for inoculation of patients. Tumor cells were irradiated $(25 \mathrm{~Gy})$ using a ${ }^{137} \mathrm{Cs}$ source, centrifuged, and a range of 17 to $56 \times 10^{6}$ tumor cells were resuspended in $0.6 \mathrm{ml}$ phosphate-buffered saline containing 250 $\mu \mathrm{g}$ granulocyte macrophage-colony stimulating factor (GM-CSF) (Sargramostim). The patients were injected intradermally on the anterior upper thigh bilaterally, and GM-CSF (125 mg) was injected intradermally into each inoculation site daily for an additional 3 days.

\section{T Cell Activation}

Inguinal LNs draining the vaccine site were surgically removed 7 days after vaccination. Lymph nodes were minced into 1 to $2 \mathrm{~mm}^{3}$ fragments, teased apart with 20-gauge needles, and filtered through nylon mesh to obtain a single-cell suspension. The LN cells were activated in X-VIVO 15 containing $10 \% \mathrm{AB}$ serum and $100 \mathrm{ng} / \mathrm{ml}$ staphylococcal enterotoxin A (SEA), at a density of 4 X $10^{6}$ cells/well in 24-well tissue culture plates, at $37 \check{\mathrm{s}} \mathrm{C}, 5 \% \mathrm{CO}_{2}$ in a humidified incubator. Two days later, cells were centrifuged, washed, and resuspended at 105/ml in X-VIVO 15 supplemented with IL-2 (60 IU/ml). Five to 8 days after initiation of $T$ cell cultures, cells were restimulated for 14 hours by incubation in tissue culture flasks coated with anti-CD3 monoclonal antibody (mAb), OKT3. Cells were subsequently adjusted to a concentration of $10^{5} / \mathrm{ml}$ and cultured in X-VIVO 15 with IL-2 (60 IU/ml) for an additional 5 to 10 days. Aliquots of cells were counted during the culture to determine the growth rate. Cultures were harvested using a modified blood cell separator and were suspended in 250 to $500 \mathrm{ml}$ of $0.9 \% \mathrm{NaCl}$ containing $5 \%$ 
dextrose, $1.25 \%$ human albumin, and IL-2 (60 IU/ml).

\section{Adoptive Cell Transfer}

Two days prior to cell infusion, patients received a single oral dose of cyclophosphamide $(10 \mathrm{mg} / \mathrm{kg})$ to facilitate survival and function of the transferred cells. Patients also received acetominophen $(650 \mathrm{mg})$ and diphenhydramine $(50 \mathrm{mg}) 30$ minutes before cell transfer. The T cells were infused through a peripheral vein over a 1-hour period while the patient remained in the outpatient clinic. Three patients also received meperidine $(50 \mathrm{mg}$ ) within 1 hour following cell infusion to treat symptoms of nausea, vomiting, or myalgia. Patients were monitored for acute toxicity for 3 hours prior to release from clinic.

\section{Toxicity and Response Criteria}

Toxicity was monitored according to National Cancer Institute Common Toxicity Criteria. Complete response was defined as disappearance of all clinical and radiographic evidence of tumor; partial response as at least a 50\% decrease in the sum of the cross-sectional areas of tumors; stable disease was defined as any change too small to quantify as either partial response or progressive disease; and progressive disease was defined as the appearance of a new lesion or an increase in the cross-sectional area of a measured lesion by more than $25 \%$.

\section{Flow Cytometry}

Cell suspensions obtained from LNs or after ex vivo stimulation were stained directly with conjugated mAb directed against CD3, CD4, CD8, CD25, and HLA-DR. Data from 10,000 stained cells were collected and analyzed on a flow microfluorometer equipped with CellQuest software.

\section{Sources of Supplies and Equipment}

The Sargramostim was kindly provided by Immunex Corp., Seattle, WA. The SEA, the human AB serum, and the enzymes used in the single-cell suspensions were obtained from Sigma Chemical Co., St. Louis, MO. The DMEM and G5 were acquired from Life Cell Technologies, Grand Island, NY. The anti-CD3 mAb, and OKT3 were obtained from Ortho Biotech., Raritan, NJ; the X-VIVO from Biowhittaker Inc., Walkersville, MD; the IL-2 from Chiron Therapeutics, Emeryville, CA; the DTI-015 from Direct Therapeutics Inc., White Plains, NY; and the stains used in flow cytometry from Becton Dickenson, Sunnyvale, CA.

The nylon mesh (Nytex) was purchased from Tetko Inc., Briarcliff Manor, NY. The blood cell separator (CS-3000) used to harvest cultures was acquired from Baxter, Deerfield IL. The software (CellQuest) and flow cytometer (FACScan) were obtained from Becton Dickenson.

\section{RESULTS}

\section{Patient Characteristics}

Ten of 11 consecutively presenting eligible patients were treated by $\mathrm{T}$ cell adoptive transfer; their characteristics are summarized in Table 1. The patient in Case 3 had recurrent Grade III astrocytoma, the patients in Cases 1 and 6 had persistent GBM following standard external-beam radiotherapy, and the other seven patients had recurrent GBM. All patients were treated with conventional radiotherapy, four of whom also received chemotherapy following their primary diagnosis. The time between surgical removal of tumor to obtain cells for the vaccine and cell infusion was typically between 10 and 14 weeks 
but varied between 7 weeks for Case 2 and 6 months for Case 1. Prior to vaccination, magnetic resonance (MR) imaging documented residual/recurrent tumor following the completion of radiotherapy in two patients (Cases 1 and 6), in whom tumor was obtained at initial diagnosis. Postoperative MR imaging demonstrated residual tumor in eight patients with recurrent tumors and in six, tumor growth was clearly apparent in the interval between surgery for recurrence and $\mathrm{T}$ cell infusion.

\begin{tabular}{|c|c|c|c|c|c|c|}
\hline & SUMlMA & OF CL & $\begin{array}{r}\text { CHARACT } \\
\text { WITR }\end{array}$ & $\begin{array}{l}\text { BLE } 1 \\
\text { S AND TREATMENT ST } \\
\text { NANT GLIOMA }\end{array}$ & IN 10 PATIE & \\
\hline $\begin{array}{l}\text { Case } \\
\text { No. }\end{array}$ & $\begin{array}{c}\text { Age }[(y r s) \\
\text { Sex }\end{array}$ & $\begin{array}{l}\text { Date of } \\
\text { Irribal } \\
\text { Sugery }\end{array}$ & Diagnosis & Iribal Treatm ent & $\begin{array}{c}\text { Date of } \\
\text { Suggery f or } \\
\text { Recurrence }\end{array}$ & $\begin{array}{l}\text { Date of } \\
\mathrm{T} \text { Cell } \\
\text { Irfusion }\end{array}$ \\
\hline $\begin{array}{c}1 \\
2 \\
3 \\
4 \dagger \\
5 \\
6 \\
7 \\
8 \ddagger \\
9 \\
10\end{array}$ & $\begin{array}{l}65, F \\
54, F \\
58, M \\
16, F \\
49, M \\
71, F \\
42, M \\
51, M \\
20, M \\
48, M\end{array}$ & $\begin{array}{r}1195 \\
1285 \\
1185 \\
789 \\
286 \\
786 \\
186 \\
1085 \\
586 \\
1285\end{array}$ & $\begin{array}{l}\text { GBM } \\
\text { GBM } \\
\text { Aू } \\
\text { GBM } \\
\text { GBM } \\
\text { GBM } \\
\text { GBM } \\
\text { GBM } \\
\text { GBM } \\
\text { GBM }\end{array}$ & $\begin{array}{l}\text { XRT } \\
\text { BCNU, XRT } \\
\text { XRT } \\
\text { XRT, gamm a knife } \\
\text { XRT } \\
\text { XRT } \\
\text { radiosurgery DT-015 } \\
\text { XRT, PCV } \\
\text { XRT } \\
\text { BCNU, CDDP, XRT }\end{array}$ & 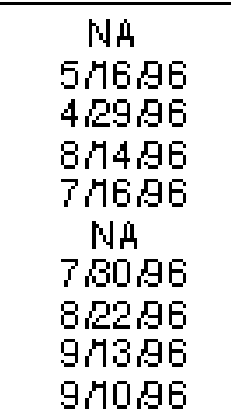 & $\begin{array}{l}5 / 1696 \\
75.96 \\
8 / 1096 \\
10 / 14.96 \\
11686 \\
11 / 1496 \\
11 / 20.96 \\
11 / 27.96 \\
12 / 286 \\
128.96\end{array}$ \\
\hline $\begin{array}{rr} & \text { c } \\
\text { procar } \\
\dagger & \text { Ini } \\
f & \text { Ini }\end{array}$ & $\begin{array}{l}\text { = cispla } \\
\text { ine, lom } \\
\text { diagno } \\
\text { diagno }\end{array}$ & $\begin{array}{l}\text { DTh-0 } \\
\text { e, wing } \\
\text { with g } \\
\text { with g }\end{array}$ & $\begin{array}{l}\text { armustin } \\
\text { xRT = } \\
\text { cytoma; } \\
\text { cytic as }\end{array}$ & $\begin{array}{l}\text { OH for in tralesional } \\
\text { al beam radiotherap } \\
\text { nt diagnosis of GBul } \\
\text { na; recurrent diagno }\end{array}$ & a not ap & $\mathrm{PCV}=$ \\
\hline
\end{tabular}

\section{Cultured Tumor Cell Vaccination}

Cultured tumor cells were used in nine patients, although in two patients (Cases 2 and 3) the cultured cells were supplemented with fresh-frozen tumor to bring the total cell dose to greater than $20 \mathrm{X} 10^{6}$. Cultured tumor cells were not available for one patient (Case 7) and fresh-frozen tumor cells were used for vaccination. Four patients (Cases 4, 5, 8, and 10) had undetectable or minimal inguinal LN enlargement following the first vaccination, and vaccination was repeated 2 weeks later; each of these patients developed a response to the second vaccination. Typically, the vaccination site had 5 to $8 \mathrm{~mm}$ of induration and a halo of erythema up to $5 \mathrm{~cm}$ in diameter. Mild tenderness and pruritus at the vaccine site occurred in several patients. The erythema subsided within 3 days after completion of the GM-CSF injections. There was no evidence of growth of tumor cells at the vaccine site in any patient through the duration of follow up.

\section{Growth of LN T Cells}

The inguinal LNs draining the vaccine site were surgically removed 7 days after vaccination and processed to a single-cell suspension. The number of cells obtained from the vaccine-draining LNs and their ex vivo growth are described in Table 2. The number of cells obtained from the LNs varied from $1.1 \times 10^{8}$ to $5.6 \times 10^{8}$ (average $2.6 \times 10^{8}$ ). The cells were activated with SEA for 2 days, and during this initial activation, the cells formed large aggregates and morphologically became lymphoblasts. The cells were washed and resuspended at a low density $\left(10^{5} / \mathrm{ml}\right)$ in serum-free media containing IL-2. The cells proliferated between seven- and 27-fold following SEA activation. Five to 8 days later, the cells were exposed to immobilized anti-CD3 mAb, and they expanded in IL-2 for an additional 5 to 10 days. 
Proliferation of $\mathrm{T}$ cells varied from a low of ninefold to a high of 350-fold. The number of activated T cells administered to the patients ranged from $9.5 \times 10^{8}$ to $1.5 \times 10^{11}$, as shown in Table 2 .

TABLE 2

SUMMARY OF RESPONSES TO YACCINATION, T CELL ACTMATION, AND CELL TRANSFER*

\begin{tabular}{|c|c|c|c|c|c|c|c|}
\hline $\begin{array}{l}\text { Case } \\
\text { No. }\end{array}$ & $\begin{array}{l}\text { Tumor Cells } \\
\text { Inoculated }\end{array}$ & $\begin{array}{l}\text { LN Cells } \\
{[\times 10]}\end{array}$ & $\begin{array}{l}\text { Culture } \\
\text { (days) }\end{array}$ & $\begin{array}{l}\text { Fold } \\
\text { Increase }\end{array}$ & $\begin{array}{l}\text { No. of Cells } \\
\text { Irfused }\end{array}$ & $\begin{array}{l}\text { Resporse } \\
\text { (duration) }\end{array}$ & $\begin{array}{c}\text { Survival } \\
\text { (mos) }\end{array}$ \\
\hline 1 & ct & 5.6 & 10 & 350 & $1.5 \times 10^{11}$ & PD & $11 \S$ \\
\hline 2 & $\mathrm{C}+\mathrm{F} \ddagger$ & 4 & 16 & 58 & $1.7 \times 10^{10}$ & PD & $7 \|$ \\
\hline 3 & $\mathrm{C}+\mathrm{F}$ & 2.3 & 15 & 22 & $3.3 \times 10^{9}$ & $\mathrm{PR}$ (4 mos) & $>15 \|$ \\
\hline 4 & $\mathrm{C}$ & 1.2 & 12 & 33 & $2.7 \times 10^{9}$ & PD & 5 \\
\hline 5 & $\mathrm{C}$ & 1.2 & 14 & 105 & $1.0 \times 10^{10}$ & PD & $>-12 \|$ \\
\hline 6 & $\mathrm{C}$ & 1.1 & 15 & 68 & $5.7 \times 10^{9}$ & PD & $9 \widehat{\S}$ \\
\hline 7 & $\mathrm{~F}$ & 3 & 14 & 229 & $6.0 \times 10^{10}$ & $\mathrm{PR}(>8 \mathrm{mos})$ & $>12 \|$ \\
\hline 8 & $\mathrm{C}$ & 1.1 & 14 & 9 & $9.5 \times 10^{8}$ & $\mathrm{PD}$ & gll \\
\hline 9 & $\mathrm{C}$ & 5.2 & 11 & 196 & $5.6 \times 10^{10}$ & PR (6 mos) & $>11 \|$ \\
\hline 10 & $\mathrm{C}$ & 1.6 & 14 & 154 & $1.7 \times 10^{10}$ & PD & $>-11 \|^{x x}$ \\
\hline
\end{tabular}

${ }^{*} \mathrm{PD}=$ progressive disease; $\mathrm{PR}=$ partial response.

$\dagger$ Patient recei ied cultured tumor cells.

† Patient recei ued frozen tumor digest.

S Time from resection of primary tumor.

Time from resection of recurrent tumor.

${ }_{x \times}$ Patient mas remo ved from study 4 months after cell transfer for additional therapy.

The vaccine-draining LNs contained mostly T lymphocytes, as shown in Table 3 . The percentage of T cells ranged from 46 to $89 \%$ with the remainder consisting mostly of B lymphocytes and monocytes. In most cases, the majority of the LN T cells were initially CD4 cells; however, in Cases 5 and 6, CD8 cells were predominant. A component of the IL-2 receptor, CD25 is expressed on recently activated T cells. The percentage of fresh LN T cells that expressed CD25 ranged from 25 to $48 \%$, indicating the presence of an active immune response within the vaccine-draining LNs. Following ex vivo stimulation, on the day the cells were administered to patients the cultures consisted entirely of T lymphocytes. The percentage of CD4 and CD8 cells was variable, and in four instances CD8 ${ }^{+}$cells were predominant in the final culture. The expression of CD25 on the cultured T cells was highly variable.

\begin{tabular}{|c|c|c|c|c|c|c|c|c|}
\hline \multirow[b]{3}{*}{ CaseNo. } & \multicolumn{7}{|c|}{$\begin{array}{c}\text { TABLE } 3 \\
\text { CHARACTERISTICS OF YACCINE-DRANNG LN CELLS }\end{array}$} & \\
\hline & \multicolumn{4}{|c|}{$\begin{array}{l}\text { Percentage of Positive } \\
\text { Fresh LN C Ells }\end{array}$} & \multicolumn{4}{|c|}{$\begin{array}{c}\text { Percentage of Positive } \\
\text { Activated Cells }\end{array}$} \\
\hline & T c ells & $\mathrm{CD} 4$ & CD8 & $\mathrm{CD} 25$ & T Cells & $\mathrm{CD} 4$ & CD8 & $\mathrm{CD} 25$ \\
\hline 1 & 73 & 67 & 7 & 45 & 100 & 81 & 14 & 98 \\
\hline 2 & 86 & 72 & 18 & 48 & 99 & 20 & 48 & 66 \\
\hline 3 & 84 & 61 & 13 & 26 & 100 & 58 & 41 & 55 \\
\hline 4 & 70 & 49 & 24 & ND & 100 & 64 & 35 & ND \\
\hline 5 & 78 & 15 & 69 & 32 & ND & ND & ND & ND \\
\hline 6 & 50 & 9 & 35 & ND & 92 & 24 & 40 & 3 \\
\hline 7 & 88 & 70 & 15 & 26 & 100 & 63 & 40 & 70 \\
\hline 8 & 89 & 69 & 19 & ND & 100 & 44 & 65 & 38 \\
\hline 9 & 80 & 58 & 23 & 25 & 100 & 15 & 89 & 29 \\
\hline 10 & 46 & ND & ND & ND & 100 & 71 & 25 & ND \\
\hline
\end{tabular}


There were no episodes of Grade 3 or 4 toxicity associated with the treatment. One patient developed, at the site of inguinal LN removal, a hematoma that resolved over several weeks. The side effects occurring within 12 hours of the cell infusion included: fever (Grade 2) in two patients; nausea/vomiting (Grade 1) in two patients; hypotension (Grade 2) in one patient; and neurocortical side effects (Grade 2) consisting of somnolence and confusion in three patients. Three patients also experienced myalgia and chills and rigors that were successfully treated with meperidine. The early side effects resolved within 12 hours and in most cases lasted fewer than 4 hours.

Five patients developed a marked increase in tumor size demonstrated on contrast-enhanced MR images 3 to 4 weeks after the T cell transfer. The clinical symptoms associated with these imaging changes included headaches and progression of preexisting neurological symptoms. Although these symptoms were transiently improved with corticosteroids, tumor progression occurred in all of these patients. Two patients underwent partial surgical resection of the mass, which demonstrated viable tumor, and T lymphocytes were identified within the resected tumor; however, it was not possible to determine whether they were transferred cells.

\section{Clinical Outcome}

All patients treated by using this protocol had residual or recurrent tumors, and clear radiographic tumor progression was demonstrated in nine patients between the time of surgery and T cell transfer. Despite active disease and rapid tumor progression prior to initiation of immunotherapy, three patients demonstrated tumor regression following immunotherapy. Stereotactic biopsy was used to diagnose the patient in Case 3 with low-grade astrocytoma of the right frontal lobe but radiographic evidence showed recurrence 3 months after diagnosis and local radiotherapy. A nearly complete surgical resection of the recurrent tumor was performed that revealed a Grade III astrocytoma; however, significant tumor growth occurred in the 3-month interval between surgery and initiation of immunotherapy. Comparison of pretreatment to follow-up MR images showed transient tumor regression following immunotherapy with tumor recurrence again noted 6 months after immunotherapy ( 9 months after surgery for recurrence) (Fig. 1). This patient received subsequent treatment with tamoxifen and is still alive 15 months after the surgery for recurrence. 


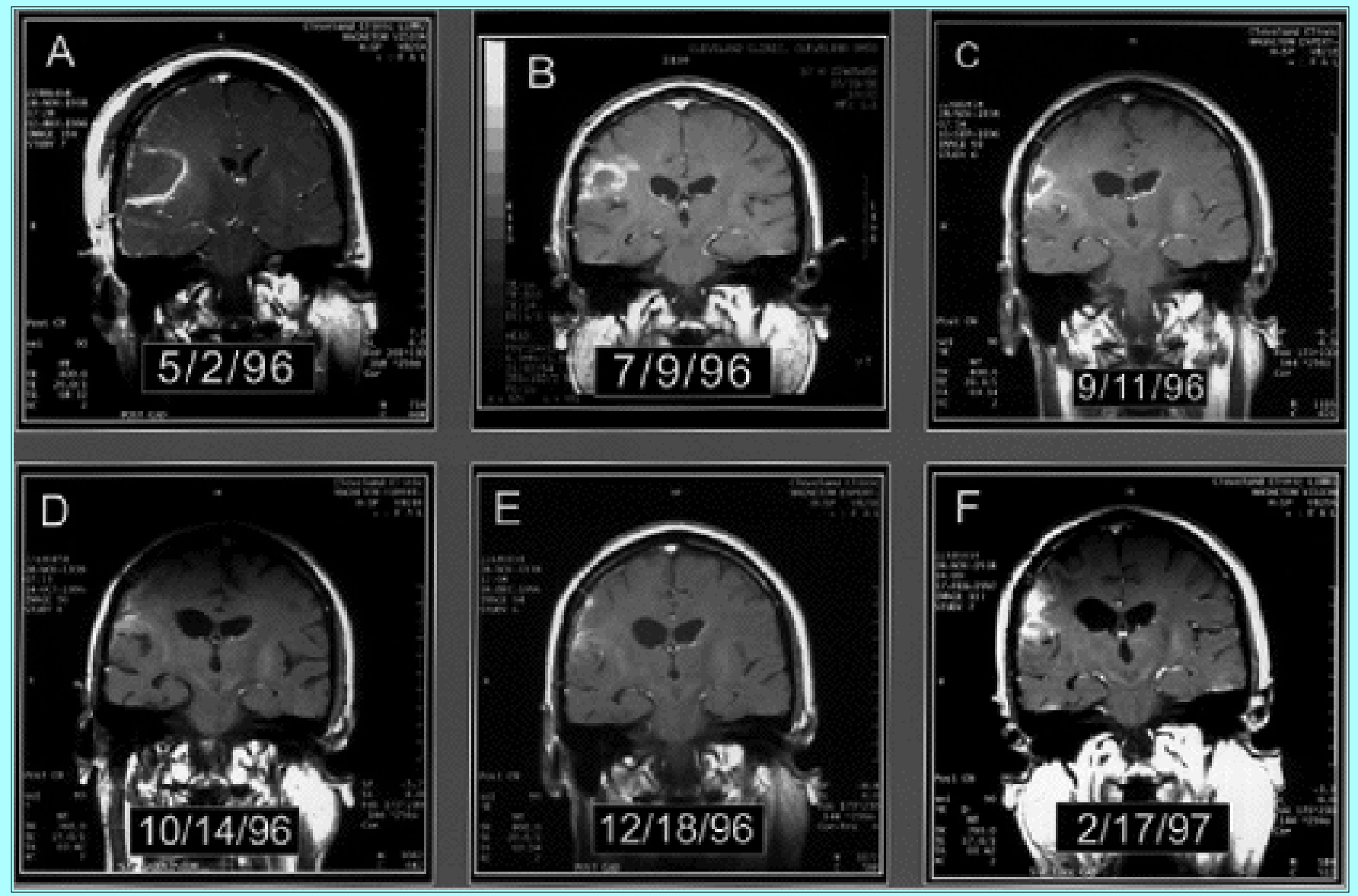

Fig. 1. Case 3. Serial MR images obtained following surgery for recurrence (A), prior to immunotherapy (B), and following T cell transfer, at 1 month (C), 2 months (D), 4 months (E), and 6 months $(\mathrm{F})$.

The patient in Case 7, diagnosed with GBM, had recurrences 3 months after surgery, conventional radiotherapy, and stereotactic radiosurgery and again 3 months following intratumoral instillation of carmustine (BCNU) in absolute ethanol, DTI-015. As shown in Fig. 2, minimal disease was apparent on postoperative MR images following surgery for recurrent tumor; however, interval progression occurred prior to immunotherapy. Subsequent imaging studies at 1,3,5, and 7.5 months after T cell transfer demonstrated partial tumor regression, with some fluctuation in levels of enhancement at the margins of tumor resection site. Clinically, more than 12 months after surgery for recurrence, this patient has remained stable with no new symptoms noted. 

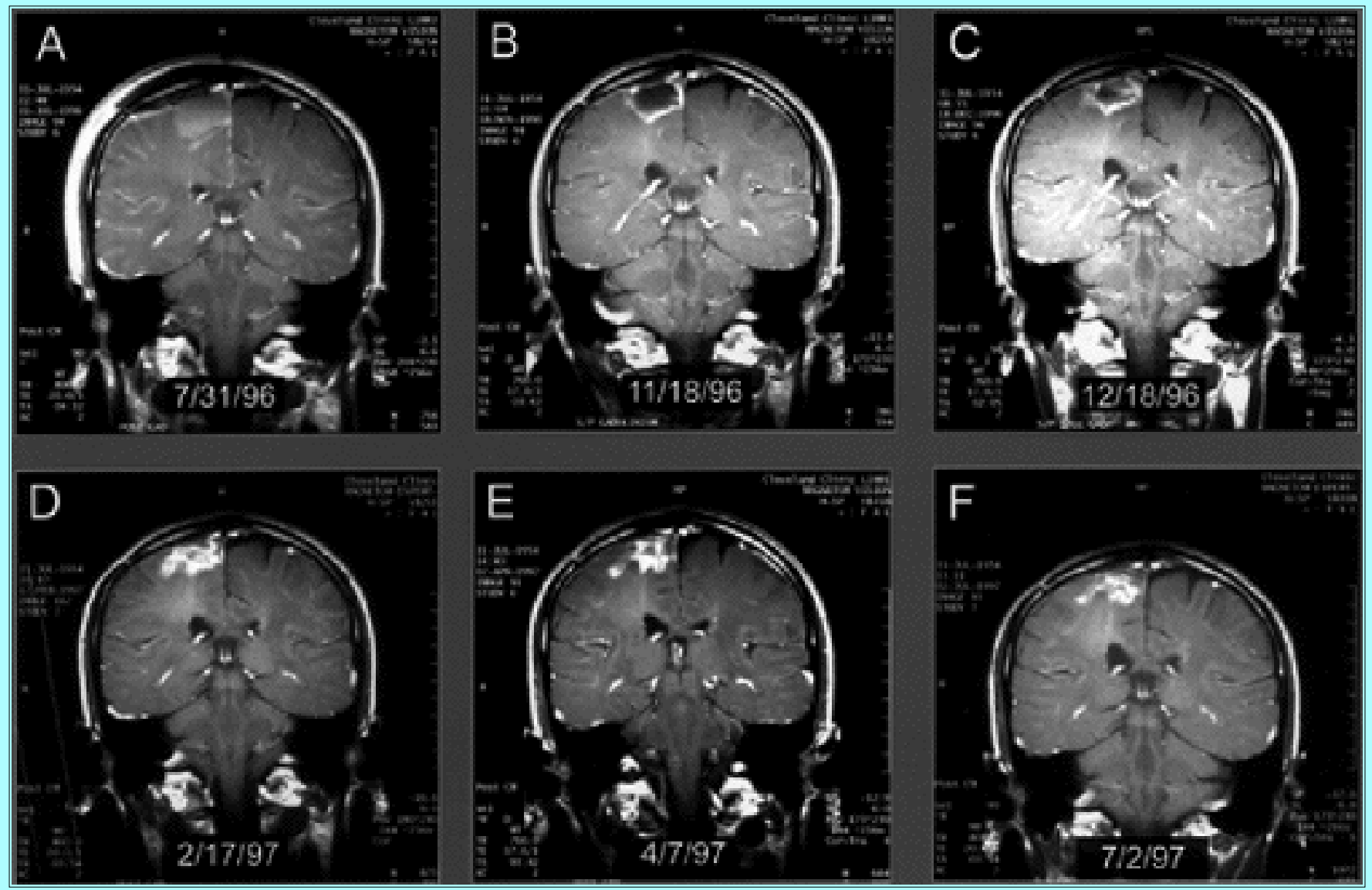

Fig. 2. Case 7. Serial MR images obtained following surgery for recurrence (A), prior to immunotherapy (B), and following T cell transfer, at 1 month (C), 3 months (D), 5 months (E), and 7 months $(\mathrm{F})$.

The patient in Case 9 underwent repeated resection of a recurrent GBM 4 months after initial diagnosis and treatment with external-beam radiotherapy. As shown in Fig. 3, residual tumor was apparent on the preimmunotherapy MR image. The patient was clinically asymptomatic following immunotherapy, and follow-up imaging at 1,3 , and 5 months after immunotherapy demonstrated resolution of residual tumor enhancement. Seven months after the T cell therapy, a massive tumor recurrence developed in the contralateral frontal lobe. However, no gross tumor recurrence was evident at the site of tumor resection. Whether the contralateral tumor represents a recurrence or a clonogenically distinct tumor is not clear. 

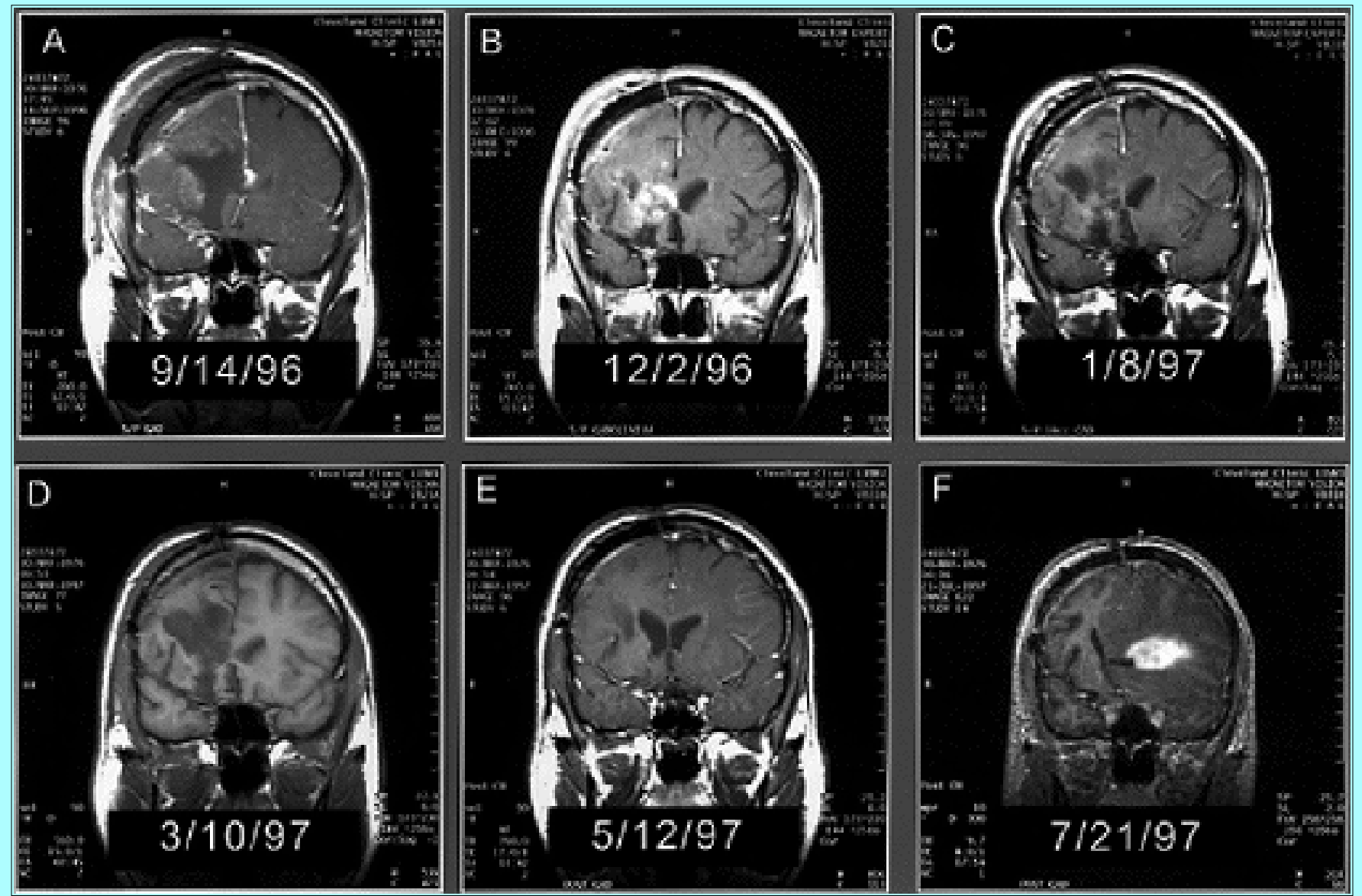

Fig. 3. Case 9. Serial MR images obtained following surgery for recurrence (A), prior to immunotherapy (B), and following T cell transfer, at 1 month (C ), 3 months (D), 5 months $(\mathrm{E})$, and 7 months $(\mathrm{F})$.

In seven patients the tumors increased in size between the date of $T$ cell transfer and the first follow-up MR image obtained within 2 months. This was associated in six patients with progression of clinical symptoms requiring the use of dexamethasone. Two patients (Cases 1 and 2) were treated with surgical debulking because of an increase in clinical symptoms approximately 4 weeks after cell transfer. These two patients subsequently experienced progressive tumor growth and died 6 months after initiation of immunotherapy. The patient in Case 10 developed tumor progression and was removed from the study 4 months after cell transfer for surgical debulking and placement of a Gliadel wafer. The patient in Case 5 exhibited rapid tumor growth $(3.5 \mathrm{X} 4.5 \mathrm{~cm})$ in the 3-month interval between subtotal resection of recurrent tumor and $\mathrm{T}$ cell transfer. Although subsequent imaging has demonstrated a slow increase in the size of tumor and/or edema, he remains alive 8 months after T cell transfer, and 12 months after surgery for recurrence, suggesting that the rate of tumor growth was attenuated.

\section{DISCUSSION}

The results of this study demonstrate the feasibility and lack of toxicity of adoptive immunotherapy for the treatment of malignant gliomas. The study design is based on overwhelming preclinical data documenting that LNs draining a progressive tumor or tumor vaccine are a rich source of tumor-sensitized T cells. A key feature of this clinical protocol is the use of autologous tumor cells to stimulate T lymphocytes in the draining LN. The antigens from malignant gliomas that are recognized by T lymphocytes have not yet been characterized, and it is not known if they are unique to each tumor or are shared. However, we reasoned that short-term cultured autologous tumor cells would likely be an 
adequate source of such antigens. The cultured tumor cells were free of necrotic cells, debris, and other types of cells; thus, they provided a more uniform vaccine preparation than frozen cells from surgical specimens. Moreover, it has been demonstrated in a previous study that tumor cells retain their antigenicity following short-term culture.[29]

Because it promotes the development and activation of antigen presenting cells, GM-CSF was chosen as an adjuvant for the tumor cell vaccine. It is currently under investigation as an adjuvant for many clinical applications and has demonstrated great promise in promoting tumor immune responses.[2,9,13,14,24,26,43,46] In patients with malignant glioma, GM-CSF induced local erythema at the vaccine site; however, in contrast to bacill Calmette-Guérin vaccine, which has been used in previous immunotherapy protocols, no local ulceration or infection was observed.[10] Additionally, tumor growth was never observed at the vaccination site, possibly because of irradiation of the vaccine and the poor metastatic capacity of gliomas. Thus, vaccination with autologous tumor and GM-CSF was feasible and well tolerated.

A number of investigations have established that there is a generalized suppression of the immune system in patients with malignant gliomas.[6,7,28,37] Initially, in our study, it was uncertain whether vaccination would induce a response in the draining $\mathrm{LN}$ for these patients. Indeed, four patients with large tumors required a second vaccination to stimulate a hyperplastic LN response. The yield of cells from the draining $\mathrm{LN}$ in these four patients averaged $1.3 \times 10^{8}$ cells, whereas the average cell yield from the remaining six patients was $3.6 \times 10^{8}$ cells. Even in the patients with a more favorable response to the vaccine, the yield of cells is depressed when compared with patients with renal cell carcinoma or melanoma receiving vaccination in similar clinical protocols.[10] Despite the existence of immunosuppression in vivo, the LN T cells responded well to ex vivo activation. A significant advantage of the ex vivo activation of $\mathrm{T}$ cells with SEA and anti-CD3 mAb is that vigorous proliferation occurred even in a low concentration of IL-2 $(60 \mathrm{IU} / \mathrm{ml})$. Biologically, SEA is probably the most potent stimulus for human T cells. Although considered a superantigen, SEA is capable of activating the majority of T cells, thus acting as a mitogen. In five patients treated on this protocol, there was a greater than 100 -fold proliferation of cells. Because the therapeutic efficacy of adoptive immunotherapy is proportional to the number of transferred cells, we hypothesize that, in addition to activating $\mathrm{T}$ cells, the numerical expansion of T cells that occurs during ex vivo culture augments the immunotherapy. The ex vivo activation with SEA and anti-CD3 mAb and IL-2 stimulated both CD4 and CD8 cell proliferation. In all cases, the percentage of CD8 cells increased during the culture, and in several cases CD8 cells were predominant at the time of infusion into patients. It has not yet been determined whether both CD4 and CD8 $\mathrm{T}$ cells are required to mediate the regression of human gliomas. Results from our experimental animal models support the hypothesis that both CD4 and CD8 T cells are required to achieve regression of intracranial tumors.[22]

To mediate tumor regression, the systemically transferred cells must migrate to the tumor and retain the capacity to respond to tumor antigens. In animal experiments, we have determined that despite the nonspecific nature of the $\mathrm{T}$ cell activation induced by SEA or anti-CD3, the cells retained their antigen specificity.[22,41,51] The use of low concentrations of IL-2 during activation is extremely important because the $\mathrm{T}$ cells lose their antigen specificity when cultured in high concentrations of IL-2 (for example, $600 \mathrm{IU} / \mathrm{ml}$ ). Adoptive immunotherapy has been used to treat many types of malignancies: for example, lymphokine-activated killer (LAK) cells generated from peripheral blood leukocytes by culture in high doses of IL-2 $(6000 \mathrm{IU} / \mathrm{ml})$ and maintained in vivo with high doses of systemic IL-2 following 
transfer. Unfortunately, clinical trials with LAK cells failed to show benefits above those observed with IL-2 only, possibly because of their poor migration to the tumor site.[3] To overcome the problem of migration to malignant brain tumors, intracavitary infusion of LAK cells or allogeneic cytotoxic T lymphocytes and IL-2 has been used in a number of clinical trials.[3,4,18,23,25,27,32,40,50] However, the results of these studies have been uniformly disappointing. Apparently, the mere presence of activated $\mathrm{T}$ cells in the tumor cavity is not sufficient to mediate tumor regression. The systemic delivery of T cells in the current protocol, in contrast with intracavitary delivery, does not pose a significant problem, provided the cells retain their ability to home to sites of antigen. In addition, because gliomas infiltrate surrounding normal brain tissue, many tumor cells may actually be physically closer to brain capillaries than the surface of the tumor cavity. It is possible that limited diffusion of $\mathrm{T}$ cells from the tumor cavity is one factor that may have limited the efficacy of intracavitary adoptive immunotherapy in previous clinical trials.

In nearly all of the previous studies of adoptive cellular immunotherapy, systemic IL-2 has been administered to patients as a conjunctional treatment. In fact, most of the toxicities associated with these treatments, particularly neurological toxicity, are attributed to IL-2.[38,39] Studies in animals with intracranial tumors have revealed that systemic IL-2 actually inhibits the efficacy of adoptive immunotherapy.[22,45] The detrimental effect of IL-2 for the treatment of intracranial tumors stands in marked contrast to its beneficial effect against tumors in other visceral organs. This unique feature of the use of systemic IL-2 in conjunction with adoptive immunotherapy possibly interfered with the therapeutic effect against brain tumors in previous clinical trials. In the current study, systemic IL-2 was not administered to the patients. Although it is not known with certainty whether IL-2 interferes with T cell migration to brain tumors in humans, the deletion of systemic IL-2 has contributed to the low toxicity exhibited in this treatment protocol.

The toxicity associated with vaccination, inguinal $\mathrm{LN}$ resection, and $\mathrm{T}$ cell infusion was minimal, and these procedures were all performed in an outpatient setting. Tumor enlargement and increased cerebral edema occurred approximately 1 month after cell transfer in three patients and could possibly represent a form of delayed toxicity. Each of these patients had significant tumor burden prior to treatment, and in two cases tumor progression was documented pathologically 1 month after cell transfer. In these cases it is not known whether the exacerbation of clinical symptoms and tumor enlargement observed on MR imaging represented the natural tumor progression, an accelerated progression of tumor growth, or edema secondary to inflammation induced by the cell transfer. Cytokines produced by T lymphocytes at sites of inflammation could contribute to vasogenic edema in the absence of glucocorticoid use. It is notable, however, that two patients (Cases 7 and 9) with radiographic and clinical responses did not develop symptoms of cerebral edema during tumor regression. It is likely that the size of the tumor and the surrounding brain's capacity to accommodate swelling would contribute to the risk of toxicity caused by inflammation and edema. These findings suggest that patients with large tumor masses or tumor located in critical brain structures may not be preferred candidates for adoptive immunotherapy.

Despite the theoretical concern regarding the development of immune reactions to shared antigens on normal brain tissue, we did not find radiographic or clinical evidence to support this possibility in any of the patients. In instances in which there was radiographic evidence of cerebral edema, it was confined to the tumor and adjacent brain. Because of the rapid progression of recurrent malignant gliomas in most of these patients, we have not yet been able to determine whether delayed autoimmune reactions against normal brain will develop as a late complication. However, unlike radiotherapy or chemotherapy in which certain side effects are unavoidable aspects of therapy, immunotherapy achieves clinical responses 
with minimal side effects.

The current protocol was designed to test whether adoptive immunotherapy with autologous LN T cells was feasible and to determine the associated toxicities. Because it is necessary for patients to be clinically stable and not receiving corticosteroids, there are brain tumor patients dependent on corticosteroids to control symptoms for whom this approach would not be possible. The generalized level of immunosuppression in these patients hampers, but does not prohibit, the feasibility of adoptive immunotherapy. The toxicities experienced by these patients appear to relate to cerebral edema and/or tumor progression and could potentially be minimized by treatment at an earlier stage of disease. It is a general principle of immunotherapy that the greater the number of cells and the less the tumor burden, the better the chance of complete tumor regression. This study was not designed to test treatment efficacy relative to controls or another therapy. However, the survival of these ten patients treated with adoptive immunotherapy compares favorably with the 23 -week median survival observed for surgery alone in patients with recurrent gliomas in a recent large clinical trial.[5] Moreover, the clinical and radiographic responses observed in three patients with recurrent malignant gliomas are very encouraging, given the tumor burden at the initiation of the treatment. Therefore, further study of adoptive immunotherapy immediately following standard surgery and radiation therapy for primary malignant glioma is warranted to determine efficacy.

\section{Acknowledgments}

The authors are are grateful to Margaret Loftus, Deborah Kangisser, and James Walsh for technical and nursing assistance.

\section{References}

1. Alexander JP, Kudoh S, Melsop KA, et al: T-cells infiltrating renal cell carcinoma display a poor proliferative response even though they can produce interleukin 2 and express interleukin 2 receptors. Cancer Res 53:1380-1387, 1993

2. Arca MJ, Krauss JC, Aruga A, et al: Therapeutic efficacy of T cells derived from lymph nodes draining a poorly immunogenic tumor transduced to secrete granulocyte-macrophage colony-stimulating factor. Cancer Gene Ther 3:39-47, 1996

3. Barba D, Saris SC, Holder C, et al: Intratumoral LAK cell and interleukin-2 therapy of human gliomas. J Neurosurg 70:175-182, 1989

4. Boiardi A, Silvani A, Ruffini PA, et al: Loco-regional immunotherapy with recombinant interleukin-2 and adherent lymphokine-activated killer cells (A-LAK) in recurrent glioblastoma patients. Cancer Immunol Immunother 39:193-197, 1994

5. Brem H, Piantadosi S, Burger PC, et al: Placebo-controlled trial of safety and efficacy of intraoperative controlled delivery by biodegradable polymers of chemotherapy for recurrent gliomas.

Lancet 345:1008-1012, 1995

6. Brooks WH, Caldwell HD, Morata RH: Immune responses in patients with gliomas. Surg Neurol 2:419-423, 1974

7. Brooks WH, Netsky MG, Normansell DE, et al: Depressed cell-mediated immunity in patients with 
primary intracranial tumors. Characterization of a humoral immunosuppressive factor. J Exp Med 136:1631-1647, 1972

8. Castelli MG, Chiabrando C, Fanelli R, et al: Prostaglandin and thromboxane synthesis by human intracranial tumors. Cancer Res 49:1505-1508, 1989

9. Chachoua A, Oratz R, Liebes L, et al: Phase Ib trial of granulocyte-macrophage colony-stimulating factor combined with murine monoclonal antibody R24 in patients with metastatic melanoma. J

Immunother 16:132-141, 1994

10. Chang AE, Aruga A, Cameron MJ, et al: Adoptive immunotherapy with vaccine-primed lymph node cells secondarily activated with anti-CD3 and interleukin-2. J Clin Oncol 15:796-807, 1997

11. Chang AE, Yoshizawa H, Sakai K, et al: Clinical observations on adoptive immunotherapy with vaccine-primed T-lymphocytes secondarily sensitized to tumor in vitro. Cancer Res 53:1043-1050, 1993 12. Chou T, Chang AE, Shu SY: Generation of therapeutic T lymphocytes from tumor-bearing mice by in vitro sensitization. Culture requirements and characterization of immunologic specificity. $\mathbf{J}$ Immunol 140:2453-2461, 1988

13. Disis ML, Bernhard H, Shiota FM, et al: Granulocyte-macrophage colony-stimulating factor: an effective adjuvant for protein and peptide-based vaccines. Blood 88:202-210, 1996

14. Dranoff G, Jaffee E, Lazenby A, et al: Vaccination with irradiated tumor cells engineered to secrete murine granulocyte-macrophage colony stimulating factor stimulates potent, specific and long-lasting anti-tumor immunity. Proc Natl Acad Sci USA 90:3539-3543, 1993

15. Fakhrai H, Dorigo O, Shawler DL, et al: Eradication of established intracranial rat gliomas by transforming growth factor ß antisense gene therapy. Proc Natl Acad Sci USA 93:2909-2914, 1996

16. Finke JH, Zea AH, Stanley J, et al: Loss of T-cell receptor zeta chain and p56 lck in T-cells infiltrating human renal cell carcinoma. Cancer Res 53:5613-5616, 1993

17. Goedegebuure PS, Douville LM, Li H, et al: Adoptive immunotherapy with tumor-infiltrating lymphocytes and interleukin-2 in patients with metastatic malignant melanoma and renal cell carcinoma: a pilot study. J Clin Oncol 13:1939-1949, 1995

18. Hayes RL, Koslow M, Hiesiger EM, et al: Improved long term survival after intracavitary interleukin-2 and lymphokine-activated killer cells for adults with recurrent malignant glioma. Cancer 76:840-852, 1995

19. Head JR, Griffin WST: Functional capacity of solid tissue implants in the brain: evidence for immunological privilege. Proc R Soc B 224:375-387, 1985

20. Huettner C, Paulus W, Roggendorf W: Messenger RNA expression of the immunosuppressive cytokine IL-10 in human gliomas. Am J Pathol 146:317-322, 1995

21. Inge TH, Hoover SK, Susskind BM, et al: Inhibition of tumor-specific cytotoxic T-lymphocyte responses by transforming growth factor ß1. Cancer Res 52:1386-1392, 1992

22. Inoue M, Plautz GE, Shu S: Treatment of intracranial tumors by systemic transfer of 
superantigen-activated tumor-draining lymph node T cells. Cancer Res 56:4702-4708, 1996

23. Jacobs SK, Wilson DJ, Kornblith PL, et al: Interleukin-2 and autologous lymphokine-activated killer cells in the treatment of malignant glioma. J Neurosurg 64:743-749, 1986

24. Jager E, Ringhoffer M, Dienes HP, et al: Granulocyte-macrophage-colony-stimulating factor enhances immune responses to melanoma-associated peptides in vivo. Int J Cancer 67:54-62, 1996

25. Kruse CA, Schiltz PM, Bellgrau D, et al: Intracranial administrations of single or multiple source allogeneic cytotoxic T lymphocytes: chronic therapy for primary brain tumors. J Neurooncol 19:161-168, 1994

26. Kwak LW, Young HA, Pennington RW, et al: Vaccination with syngeneic, lymphoma-derived immunoglobulin idiotype combined with granulocyte/macrophage colony-stimulating factor primes mice for a protective T-cell response. Proc Natl Acad Sci USA 93:10972-10977, 1996

27. Lillehei KO, Mitchell DH, Johnson SD, et al: Long-term follow-up of patients with recurrent malignant gliomas treated with adjuvant adoptive immunotherapy. Neurosurgery 28:16-22, 1991

28. Mahaley MS Jr, Brooks WH, Roszman TL, et al: Immunobiology of primary intracranial tumors. Part 1: studies of the cellular and humoral general immune competence of brain-tumor patients. $\mathbf{J}$ Neurosurg 46:467-476, 1977

29. Matsumura T, Sussman JJ, Krinock RA, et al: Characteristics and in vivo homing of long-term T-cell lines and clones derived from tumor-draining lymph nodes. Cancer Res 54:2744-2750, 1994

30. Maxwell M, Galanopoulos T, Neville-Golden J, et al: Effect of the expression of transforming growth factor- $\$ 2$ in primary human glioblastomas on immunosuppression and loss of immune surveillance. J Neurosurg 76:799-804, 1992

31. Medawar PW: Immunity to homologous grafted skin. III. The fate of skin homografts transplanted to the brain, to subcutaneous tissue, and to the anterior chamber of the eye. Br J Exp Pathol 29:58-69, 1948

32. Merchant RE, Merchant LH, Cook SHS, et al: Intralesional infusion of lymphokine-activated killer (LAK) cells and recombinant interleukin-2 (rIL-2) for the treatment of patients with malignant brain tumor. Neurosurgery 23:725-732, 1988

33. Peng L, Shu S, Krauss JC: Treatment of subcutaneous tumor with adoptively transferred T cells. Cell Immunol 178:24-32, 1997

34. Plautz GE, Inoue M, Shu S: Defining the synergistic effects of irradiation and T-cell immunotherapy for murine intracranial tumors. Cell Immunol 171:277-284, 1996

35. Plautz GE, Touhalisky JE, Shu S: Treatment of murine gliomas by adoptive transfer of ex vivo activated tumor-draining lymph node cells. Cell Immunol 178:101-107, 1997

36. Rosenberg SA, Packard BS, Aebersold PM, et al: Use of tumor-infiltrating lymphocytes and interleukin-2 in the immunotherapy of patients with metastatic melanoma. A preliminary report. $\mathbf{N}$ Eng $\mathbf{J}$ Med 319:1675-1680, 1988 
37. Roszman TL, Brooks WH: Immunobiology of primary intracranial tumors. III. Demonstration of a qualitative lymphocyte abnormality in patients with primary brain tumors. Clin Exp Immunol 39:395-402, 1980

38. Saris SC, Patronas NJ, Rosenberg SA, et al: The effect of intravenous interleukin-2 on brain water content. J Neurosurg 71:169-174, 1989

39. Saris SC, Rosenberg SA, Friedman RB: Penetration of recombinant interleukin-2 across the blood-cerebrospinal fluid barrier. J Neurosurg 69:29-34, 1988

40. Sawamura Y, Hosokawa M, Kuppner MC, et al: Antitumor activity and surface phenotypes of human glioma-infiltrating lymphocytes after in vitro expansion in the presence of interleukin 2. Cancer Res 49:1843-1849, 1989

41. Shu S, Krinock RA, Matsumura T, et al: Stimulation of tumor-draining lymph node cells with superantigenic staphylococcal toxins leads to the generation of tumor-specific effector T cells. J Immunol 152:1277-1288, 1994

42. Shu S, Chou T, Rosenberg SA: Generation from tumor-bearing mice of lymphocytes with in vitro therapeutic efficacy. J Immunol 139:295-304, 1987

43. Simons JW, Jaffee EM, Weber CE, et al: Bioactivity of autologous irradiated renal cell carcinoma vaccines generated by ex vivo granulocyte-macrophage colony-stimulating factor gene transfer. Cancer Res 57:1537-1546, 1997

44. Sussman JJ, Shu S, Sondak VK, et al: Activation of T lymphocytes for the adoptive immunotherapy of cancer. Ann Surg Oncol 1:296-306, 1994

45. Sussman JJ, Wahl WL, Chang AE, et al: Unique characteristics associated with systemic adoptive immunotherapy of experimental intracerebral tumors. J Immunother 18:35-44, 1995

46. Tao MH, Levy R: Idiotype/granulocyte-macrophage colony-stimulating factor fusion protein as a vaccine for B-cell lymphoma. Nature 362:755-758, 1993

47. Wahl WL, Sussman JJ, Shu S, et al: Adoptive immunotherapy of murine intracerebral tumors with anti-CD3/interleukin-2-activated tumor-draining lymph node cells. J Immunother 15:242-250, 1994

48. Walker MD, Alexander E Jr, Hunt WE: Evaluation of BCNU and/or radiotherapy in the treatment of anaplastic gliomas: a cooperative trial. J Neurosurg 49:333-343, 1978

49. Walker MD, Green SB, Byar DP, et al: Randomized comparisons of radiotherapy and nitrosoureas for the treatment of malignant gliomas after surgery. N Engl J Med 303:1323-1329, 1980

50. Yoshida S, Tanaka R, Takai N, et al: Local administration of autologous lymphokine-activated killer cells and recombinant interleukin 2 to patients with malignant brain tumors. Cancer Res 48:5011-5016, 1988

51. Yoshizawa H, Chang AE, Shu S: Specific adoptive immunotherapy mediated by tumor-draining lymph node cells sequentially activated with anti-CD3 and IL-2. J Immunol 147:729-737, 1991

Manuscript received September 15, 1997. 
Accepted in final form October 17, 1997.

Address reprint requests to: Suyu Shu, Ph.D., Center for Surgery Research FF5, The Cleveland Clinic Foundation, 9500 Euclid Avenue, Cleveland, Ohio 44195.

This work was supported in part by USPHS Grant Nos. RO1 CA 74919 and RO1 CA 73834 from the National Cancer Institute, and the Immunex Corporation. 